\title{
THE EFFECT OF A TEACHER-DESIGNED ASSESSMENT TOOL ON AN INSTRUCTOR'S COGNITIVE ACTIVITY
}

\author{
Andrew Cohen ${ }^{*}$, Katie Candland ${ }^{\dagger}$, Elizabeth Lee ${ }^{*}$ \\ ${ }^{*}$ Centre for Applied Cognitive Science \\ OISE-252 Bloor Street West \\ Toronto, Ontario, CANADA M5S 1V6 \\ andrew_cohen@cacsmail.oise.on.ca \\ †Apple Computer, Inc. \\ 1 Infinite Loop \\ Cupertino, California 95014 \\ katie@taurus.apple.com
}

KEYWORDS: activity theory, CSILE, education, interface, participatory design, teacher

\begin{abstract}
This paper examines how the design and addition of a software tool to an existing computer network learning environment shifts the overall activity of teaching and assessment. We introduce a learning environment developed by Scardamalia, Bereiter, McLean, Swallow \& Woodruff (1989) called Computer-Supported Intentional Learning Environment, (CSILE). We examine the shift in activity within the context of Leontiev's theory of human activity, attempting to show, through a detailed case study, the relationship between the introduction of a new software tool and a shift in human activity.
\end{abstract}

\section{INTRODUCTION}

Computer-Supported Intentional Learning Environment (CSILE) is a computer-mediated environment developed to support a problem-based curriculum and foster intentional learning (Bereiter \& Scardamalia, 1989) and progressive discourse (Bereiter, 1994). In CSILE, students use a computer database system as a tool to store and organize their curriculum-related knowledge, and to share information and thoughts with peers (Scardamalia, Bereiter, McLean, Swallow \& Woodruff, 1989). Using a network of microcomputers in their classroom, students can create text and graphic notes, develop joint discussions, comment on others' work, and link together complexes of notes to further develop their knowledge. The learning context in the classroom is altered so that students pursue their knowledge through peer collaboration, with their teacher as a learning expert who coaches them to become expert learners. Where CSILE has been successful, the role of discourse in knowledge construction is recognized and the emphasis is on problem-centered learning; this is what Bereiter and Scardamalia (1989) call a knowledge building community.

This paper describes the implementation of a userdesigned software tool, created to meet the particular needs of one group of users in CSILE - the teachers. We seek to supply evidence for the value of involving the user in the design of tools which are intended to help the user shift his or her beliefs, as opposed to a traditional top-down approach of imposing change on teachers. In the following section, we address specific problems that teachers have in becoming effective participants in, and coaches of a knowledge building community. We describe the user-centered design and development of a software tool, the Teacher Assessment Tool (TAT), and the results of a case study, examining, in detail, the use of the tool and its effect on the activities of a particular teacher.

\section{THE TEACHER'S ROLE}

In order to provide the cognitive support to coach students, the teacher must participate not just in the learning of one set of problems or with only one set of students, but with the whole class. To do this with CSILE requires a high level of teacher interaction with the database. The teacher must not only pay attention to what and how the students are doing on a regular basis, but must also focus on students' progressive paths through problems. Essentially, teachers need to follow and contribute to activity in the database in order to sustain progress in understanding. They need to reflect on students' progress and on their own participation in the process in order to develop a personal understanding of the on-going knowledge building activity and to evolve actions that sustain and enrich this process. 
Teachers have difficulty examining the database in a way they would like because the CSILE interface was developed for the students. It does not support the type of visualizations of evolving database structure (complexes of comments, responses, and linked notes), systematic investigation of student work, or graphic representations of general database activity which would help the teacher participate in the activity of the whole class. Teachers must search and then read students' notes individually, following the chains of comments, responses, and links made in the database. This is time-consuming and cumbersome when it must be done for all topics and all students.

\section{THE TEACHER ASSESSMENT TOOL}

In order to design an assessment tool that would facilitate higher-level activity among teachers using CSILE, we involved nine teachers at three CSILE sites in a participatory design process. Over a three month period, we engaged in a series of task analyses, group meetings, and user tests of four functional iterations of a prototype. In this way, the design of TAT was informed by the teachers' ideas for improving the activities of coaching and assessing knowledge building in the database.

The resulting teacher-designed CSILE assessment tool (TAT) includes the following features. A progressive database query allows the teacher to define the parameters of the assessment. Any number of queries can be defined while the tool is in use. An overview graph shows the number of notes, comments, and discussions for each student in the class. Tables display various attributes of an individual student's notes. Tree-like diagrams called note trees illustrate the attributes of and relationships between notes, comments, and links in the CSILE database. The attribute tables and note trees provide entry to the CSILE database and allow the teacher to open individual or specified groups of notes. TAT was designed to be extendible, allowing for easy implementation of additional features in the future.

This paper details the testing of TAT. The three research questions are: (1) Does this intervention facilitate more involvement by the teacher in the database? (2) Does this intervention facilitate better involvement in the database? (3) Does this intervention facilitate a shift from a referent-based assessment and coaching role to a more problembased assessment and coaching role in teaching with CSILE? Further, this analysis will examine the relationship between the amount of involvement, quality of involvement and the shift in belief and activity. Activity theory, particularly the work of Leontiev, provides a framework for systematically examining the relationship between levels of analysis and how different levels of analysis help us understand thinking and learning.

\section{ACTIVITY THEORY}

Leontiev (Leontiev, 1981), proposed three strata of human activity, 'activity' which refers to the "motive" of social action; 'action', which refers to the intentional "goals" of actors within an activity setting, and 'operation', which refers to the "conditions" or real behaviors of actors in the carrying out of actions within an activity. Applying Leontiev's categories 'operations' are the basic operations performed on the database, such as a particular search or retrieval, or the manner of input, text or graphic; 'actions', being goal-related, are built up from operations. Actions can be commenting, or writing notes or drawing graphics, or conducting a goal-directed set of searches or retrievals. The overall 'activity' is driven by the teacher's model of and beliefs about teaching and assessment (Wells, 1993).

In this particular activity system, the addition of TAT to CSILE changes the operations available to the teacher using CSILE. The tool changes the conditions under which goals can be developed. These actions change in ways specifically designed by the teacher. A new set of actions change the goals the teacher can set which, in turn, can affect the overall activity. We must return to our research questions to directly address the benefit of using Leontiev's strata of activity to answer our research questions.

The three research questions (above) relate to the three different strata theorized by Leontiev as follows. The first question deals directly with the condition under which the teacher is working, mainly, that a new instrument, TAT, allows different operations on the database. For example, the ability to search and retrieve with specific parameters may improve the teacher's ability to navigate and access a greater amount of the database. The second question deals directly with the available actions and how they might relate to the goals of the teacher. For example, is the teacher writing comments that focus on students' understanding? Is the teacher able to build up individual searches and retrievals into goal directed actions? The third question deals directly with the level of activity. Can the use of a teacher-designed tool help facilitate a shift in beliefs in the teacher? 


\section{METHODOLOGY}

\section{Subjects \& Procedure}

We conducted a study of the CSILE Teacher Assessment Tool with four of the teachers who had participated in the design of the tool (all teachers taught fifth and sixth grade classes). All the teachers had previously used CSILE in their classrooms and had expressed interest in finding better ways to track and assess their students' work in CSILE. Data was gathered for each teacher in the user study; however, we report here detailed findings on one teacher's use of TAT and provide more general data from the total sample of users to support our assertions.

All the teachers agreed to use the CSILE assessment tool for at least one half hour per week in conjunction with their on-going use of CSILE in the classroom. For the intervention phase, the teachers agreed to do all their assessment via TAT. Three teachers at one site used TAT for a period of four weeks; one teacher at another site used it for a period of eight weeks.

\section{Design/Data Collected}

Three different types of data were collected before and throughout the intervention phase. These data were designed to enable us to characterize changes in the teacher's operations, actions, and shifts in activity.

Both CSILE and TAT save isomorphic sets of quantitative tracking data detailing user operations on the database, such as information on the number and types of searches, retrievals, and sessions. This tracking data was collected on a weekly basis on the teachers from CSILE for the academic year preceding the introduction of TAT and from TAT for the time period while the teachers were using TAT.

Teachers' comments on students' notes in the database indicate whether the teacher's involvement in the database is of the type that will sustain, enrich, and engage the knowledge building community. The content of the teacher's comments allow inferences to be made as to whether the teacher's 'actions' are based on referent-centered knowledge building goals (i.e. "It looks like you are making real progress on discovering stuff about the language. Keep up the good work. ... Also, have you learned anything about the language of the Hula dance?") or problem-centered goals (i.e. "In your note, 'From where did the language come?' You say, 'Then things changed.' I am curious. What changed? What happened to change things? Could you say more in your note, please, about what this change was?"). Teachers' comments in CSILE were collected on a weekly basis for the academic year preceding the introduction of TAT and for the time period while the teachers were using TAT. Comments were parsed into idea units and categorized into one of the following: (1) referent-centered knowledge - the teacher aims to discover and evaluate general productivity, declarative knowledge, or rote learning; (2) problem-centered knowledge - the teacher aims to discover, participate in, or evaluate thinking, understanding, and learning; (3) metacognitive - the teacher reflects on the students' thinking and learning as well his/her own and the role s/he plays in the construction of knowledge in the CSILE database.

We developed two interviews designed to elicit teachers' models of teaching and assessment, a long pre-intervention interview and a short interview. The interviews were based on Bereiter and Scardamalia's (1987) teachers' models of teaching but the responses were parsed into idea units and scored into the same categories as those for comments. Prior to introducing TAT into classrooms, we conducted the long pre-intervention interview with each teacher. Short interviews were conducted with each teacher on a biweekly basis throughout the intervention period.

\section{RESULTS}

Using Leontiev's work as a theoretical basis, we attempt to answer our research questions on the basis of the case study data from one teacher. We will analyze each set of data, discussing the relationship between the data, the research question, and strata of activity to which the data relates.

Changes in the amount of teacher involvement in the CSILE database as a result of using TAT allow us to characterize changes at the level of operation and, to some extent, changes at the level of action. The teacher opened significantly more notes on a per student basis while using TAT (average: 4.3 vs. 1.3, respectively), (t, 4.31; $\mathrm{P}<0.001)$. Correlated with this is the fact that with TAT, the teacher increased the number of students for whom she opened at least one note. Before the introduction of TAT, the teacher looked at notes from only $60 \%$ of her students, even though many of the other students had written a significant number of notes. The number of students investigated increased to greater than $87 \%$ while using TAT. Additionally, the teacher followed more links and comments per week while using TAT than with CSILE, (average: 4.62 vs. 1.5 , respectively), (not sig.). Similar trends exist on an average, per week basis for the other three teachers for the number of notes opened, (average: 18.75 vs. 9.17, 
respectively) and notes and links followed, (average: 4.62 vs. 1.5 , respectively).

The change in the teacher's operations indicates an increase in the teacher's practical exploration and involvement in the CSILE database. This data directly relates to our research question: (1) Does this intervention facilitate more involvement by the teacher in the database? We clearly see an increase, more involvement in the database by the teacher. To some degree these changes in operations may imply a change in the teacher's actions ("goals") related to coaching and assessing knowledge building in the community. This relates to our second research question: (2) Does this intervention facilitate better types of involvement in the database? In particular, an increased investigation of students in the database implies that the tool is helping the teacher move toward better types of involvement in the database.

Changes in the quality of the teacher's involvement in the database allow us to characterize changes at the action level, resulting from the use of TAT. One of the primary ways in which the teacher participates in, and contributes to the knowledge building of the community is through the comments s/he makes in the CSILE database. The content analysis of the teacher's comments for the two periods revealed that the number of referent-centered comments dropped over $21 \%$; the number of comments focusing on problem-centered knowledge building goals increased almost 4\%; while the number of metacognitive comments increased almost $17 \%$.

This shift in the type of comments made by the teacher while using TAT indicates a shift from referent-centered knowledge building goals to problem-centered knowledge building goals. This allows us to give a positive answer to our second research question: (2) Does this intervention facilitate better types of involvement in the database?

Changes in the teacher's beliefs and model of teaching allow us to infer a possible change in activity as a result of using TAT. Results of the content analysis on both sets of interview data reveal that for the long initial interview, the majority, $60.8 \%$, of the teacher's description of her beliefs and behavior fell into the referent-based model of learning, while $16.2 \%$ of the teacher's description of her beliefs and behavior fell into the model of learning which emphasizes assessment of problemcentered knowledge; the remainder, $12.1 \%$, fell into the model of learning that focuses on reflection about thinking and understanding, or metacognition. About
$10.8 \%$ of the teacher's statements were not codable. Analysis of the eight biweekly interviews using the cognitive assessment categories indicates the occurrence of a shift in the teacher's model of assessment during the intervention period. While the shift most likely took place gradually in the teacher, the change in category 1 and 2 responses between the first and second half of the intervention period is remarkable. In the first half of the intervention period, $51.5 \%$ of the teacher's responses are in category 1 and $28 \%$ are in category 2 . In the second half of the intervention period, category 1 responses are $12.9 \%$ and category 2 responses are $67.7 \%$. A similar shift can be seen from the pre-intervention interview to the second half of the biweekly interviews.

This data suggest that the use of TAT led the teacher to change her beliefs about teaching and assessment activity in the CSILE database from a mostly referent-centered model to one more concerned with problem-centered knowledge building.

\section{DISCUSSION}

Bereiter (1992), proposed that schooling should engage students in extended high-level problems which then serve as the organizing points for knowledge construction; however, in order for this to happen, the model of learning held and practiced by teachers must be one that energetically fosters such an activity. The history of research on teachers indicates that attempts to transform teachers' models of learning are rarely successful. It is here that educational research and research on human-computer interaction intersect. In the present investigation, information technology is used as the primary vehicle to create the educational environment for the classroom, and to actively engage the teacher in solving her problems as a teacher.

The primary purpose of this paper was to examine a detailed case of a teacher shifting her activity through the design and use of a new software tool, TAT. Our aim was to establish that teacher change can be motivated by engagement in the design of new operations (in this case, by way of a new software tool) that they can perform on a CSILE database. We have detailed three sets of data relevant to Leontiev's three strata of human activity. They indicate that, at the operations level, there is an increase in the number of notes opened, and the number of links and comments followed. Clearly there is more involvement in the database by the teacher. At the actions level, we see an increase in the number of 
students investigated in the database, and a shift from referent-based work toward more problem-centered and metacognitive work in the type of comments the teacher made to her students. These imply that the tool is helping the teacher move toward better types of involvement in the database. At the activity level, we see indications of a change in the teacher's model of teaching and assessment activity in the CSILE database from a mostly referent-centered model to one more concerned with problem-centered knowledge building and reflection on the process of problemcentered knowledge building or metacognition. This portion of the data suggests that the intervention facilitates $a$ shift in belief from a referent-based assessment and coaching role to a more problembased assessment and coaching role.

As demonstrated by the results, there are indeed impressive changes at the operations level, and at the action level, and there seem to be changes in the level of activity of the teacher under study. The overarching goal of this work is to demonstrate a teacher's involvement in the solution of problems she identifies as a teacher; and to show that, given the necessary support to analyze and follow student work, the teacher is more able to set and accomplish the goals of knowledge building. Further analysis of the other teachers in the study would allow more general results to be derived. However, this study is significant both for its implications as a method of approaching teacher change from the viewpoint of the teacher, and for the field of human-computer interaction research, in particular, for the issue of shifts in cognitive activity as the result of the use of specific software tools.

\section{Acknowledgments}

Support for this research has been provided by the McDonnell foundation, the province of Ontario, and the CSILE project. Special thanks to Marlene Scardamaila and Carl Bereiter for conceptual ideas and guidance, to Gordon Wells for theoretical discussions and comments, to Alan Rosenthal for coding the network libraries, to Peter Rowley for technical assistance, and, of course, to all the teachers who participated in this project.

\section{REFERENCES}

Bereiter, C. (1994) Implications of Postmodernism for Science, or, Science as Progressive Discourse. Educational Psychologist, vol. 29 (1), pp. 3-12.

Bereiter, C. \& Scardamalia, M. (1987) An Attainable Version of High Literacy: Approaches to Teaching Higher Order Skills in Reading and Writing. Curriculum Inquiry, vol. 17 (1), pp. 9-39.

Bereiter, C. \& Scardamalia, M. (1989) Intentional Learning as a Goal of Instruction. In L. B. Resnick (Ed.) Knowing, learning, and instruction: Essays in Honor of Robert Glaser. Lawrence Erlbaum Associates. Hillsdale, NJ. pp. 361-392.

Leontiev, A. N. (1981) The problem of activity in psychology. In J. V. Wertsch (Ed.) The concept of activity in Soviet psychology. Sharpe. Armonk, NY.

Scardamalia, M., Bereiter, C., McLean, R. S., Swallow, J. \& Woodruff, E. (1989) Computersupported intentional learning environments. Journal of Educational Computing Research, vol. 5 (1), pp. 51-68.

Scardamalia, M., \& Bereiter, C. (1991) Higher Levels of Agency for Children in Knowledge Building: A Challenge for the Design of New Knowledge Media. The Journal of the Learning Science, vol. 1 (1), pp. 37-68.

Wells, G. (1993) Re-Evaluating the IRF Sequence: A Proposal for the Articulation of Theories of Activity and Discourse for the Analysis of Teaching and Learning in the Classroom. Unpublished Manuscript. 